\title{
Electron microscopic studies of growth of nanoscale catalysts and soot particles in a candle flame
}

\author{
Wu Zong Zhou $\cdot$ Feng Jiao Yu • Heather F. Greer • \\ Zheng Jiang $\cdot$ Peter P. Edwards
}

Received: 29 June 2012 / Accepted: 31 July 2012/Published online: 18 August 2012

(c) The Author(s) 2012. This article is published with open access at Springerlink.com

\begin{abstract}
Scanning electron microscopy and high-resolution transmission electron microscopy have been used to investigate non-classic crystal growth of catalytic nanoparticles, such as zeolites, perovskites, metal and alloy particles. Growth mechanisms of some crystals with novel morphologies, for example, $\mathrm{BiOBr}$ flower-like particles and $\mathrm{ZnO}$ twin-crystals, have also been studied. A development of sampling method for soot particles inside a candle flame allows us to reveal all four well-known carbon forms, amorphous, graphitic, fullerenic and nanodiamond particles. This article demonstrates that electron microscopy is a powerful tool to study the microstructures of small particles, giving us more freedom to develop new materials.
\end{abstract}

Keywords Crystal growth $\cdot \mathrm{ZnO} \cdot \mathrm{BiOBr} \cdot \mathrm{CaCO}_{3}$. Electron microscopy

\section{Introduction}

Development of catalysts is an important field in petrochemical research. Every year, a large number of new catalysts with various morphologies are reported. However, our knowledge of the formation mechanisms of these crystalline materials is still very limited. One of the reasons is that people normally admire the beauty of these final

W. Z. Zhou $(\bowtie) \cdot$ F. J. Yu · H. F. Greer

School of Chemistry, University of St Andrews, St Andrews, Fife KY16 9ST, UK

e-mail:wzhou@st-andrews.ac.uk

Z. Jiang · P. P. Edwards

Inorganic Chemistry Laboratory, Department of Chemistry, University of Oxford, Oxford OX1 3QR, UK products and their catalytic performance, but pay less attention to the way they form.

Growth of a free crystal can be well described using the classic theory established 100 years ago, i.e. a nucleation step followed by a layer-by-layer deposition of the building units, which can be atoms, or ions, or molecules. Its morphology can be predicted by the Bravais-Friedel-DonnayHarker (BFDH) law: the final polyhedral morphology is formed by slow-growing faces (with large $d$-spacings), because all the fast-growing faces (with small $d$-spacings) would grow out during the process [1-3]. For example, the largest $d$-spacing in zeolite analcime corresponds to the (211) planes, therefore, both the natural and synthetic crystals of analcime have an icositetrahedral shape consisting of $24\{211\}$ facets. Another obvious fact in this kinetically controlled mechanism is that the particle at any stage during the growth should be a single crystal. But when we examined the intermediate specimens at early stages of a crystal-growth process, we found the classic theory of crystal growth was not always followed. Herein, we demonstrate some examples of non-classic crystal growth and what we learnt from scanning and transmission electron microscopic (TEM) images of particles before their maturity.

\section{Reversed crystal-growth route}

The classic theory of crystal growth has been used for over one century and it seems to be very successful in explaining the relation between crystal morphologies and their corresponding crystal structures. This was why when we saw a perfect icositetrahedral particle of analcime synthesised in a system with $\mathrm{C}_{2} \mathrm{H}_{5} \mathrm{NH}_{2}$, we had no reason to doubt its single-crystal state, until its single-crystal 

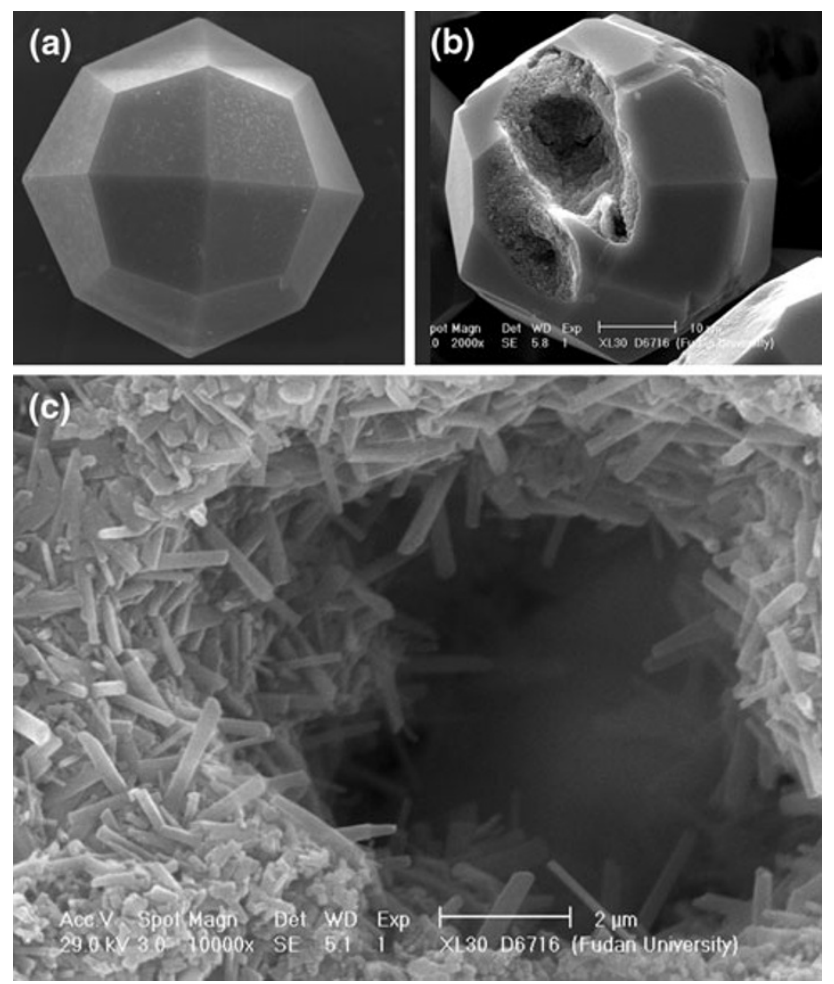

Fig. 1 SEM images of synthetic zeolite analcime. a An icositetrahedral particle. b An intentionally broken icositetrahedron showing polycrystalline core. c Enlarged image of the core nanorods [4]

X-ray diffraction pattern showed a strong polycrystalline ring. Figure 1a shows a scanning electron microscopic (SEM) image of such a crystal with about $50 \mu \mathrm{m}$ in diameter.

When we made a hole in a crystal which had a perfect icositetrahedral morphology, the core was revealed to be actually polycrystalline, containing randomly oriented nanorods (Fig. 1b, c). This discovery encouraged us to examine the details of the crystal growth step-by-step. At the beginning, it was found that when the analcime crystals grew into very small nanoplates about $20 \mathrm{~nm}$ in diameter, they started to aggregate into large spherical particles. $\mathrm{C}_{2} \mathrm{H}_{5} \mathrm{NH}_{2}$ played an important role in aggregation. In this case, most crystallites inside the microspheres lost their original environment for crystal growth. The most active sites were on the surface of the spheres or in the interface between the spheres and the solution. As a result, recrystallization took place on the surface of the spheres to form many monocrystalline islands. These islands grew up, joined together with adjusted orientations to form a very thin single-crystal shell with perfect polyhedral morphology (Fig. 1a). Re-crystallization then extended from surface to the core and finally achieved a real single-crystal state [4].

This so-called reversed crystal-growth route was later found in other systems, such as zeolite A [5, 6], perovskites
$\mathrm{CaTiO}_{3}$ and $\mathrm{BaTiO}_{3}[7,8]$, metal [9] and alloy particles (F. J. Yu et al. paper under preparation). Recently, it was also found in organic crystals [10].

Zeolite A is an important industry catalyst. When biopolymer chitosan was used as a non-structure directing agent, microcubes of zeolite A were produced without any notable difference to those prepared using the traditional synthetic method. However, we found chitosan induced aggregation of precursor molecules even before nucleation occurred. Consequently, cubic particles had a core-shell structure, an amorphous core covered by a single-crystal shell of only a few nanometers thick as shown in the TEM images in Fig. 2 [6]. After acid treatment, the amorphous cores were removed, leaving very thin zeolite A boxes or hollow cubes. This novel morphology can be easily achieved via the reversed crystal-growth route.

Many hollow crystals have been fabricated in the last 20 years. However, their formation mechanism can only be fully understood when the structure evolution is investigated in steps. We took hollow crystals of perovskite $\mathrm{CaTiO}_{3}$ as an example. In a poly(ethylene glycol) 200 (PEG-200) solution, $\mathrm{CaTiO}_{3}$ nanocubes formed first. The nanocubes underwent oriented self-assembly into spherical particles, enhanced by the surface-adsorbed polymer molecules. These polycrystalline spheres had a relatively low density compared to single crystals. Surface re-crystallization then took place to increase their density and create a high-crystallinity shell. The nanocubes in the core gradually disappeared via an Ostwald ripening process and finally led to hollow crystals (Fig. 3) [7]. Understanding the complete formation mechanism of these hollow $\mathrm{CaTiO}_{3}$ crystals would enable us to control the microstructures of these materials and to explain the formation of many other hollow crystals. Water agate stones are typical natural hollow crystals, which might form with exactly the same mechanism [11].

It is interesting to see such a reversed crystal growth is also a true process in nanomaterials. In fact, several years before the discovery of this non-classic mechanism, we found the formation of cobalt nanocrystallites as a catalyst for $\mathrm{Mg}_{2} \mathrm{SiO}_{4}$ fishbone-like fractal nanorods followed a nonclassic route [9]. When Co nanocrystallites grew up to about $2 \mathrm{~nm}$ in size, they aggregated on the surface of $\mathrm{Mg}_{2} \mathrm{SiO}_{4}$, without the presence of any organic surfactants in this solid-gas reaction system. Only when the aggregates increased their size to over $100 \mathrm{~nm}$, did they recrystallize into single crystals with a cubic morphology. In more recent work, we have obtained clear evidence of a surface to core extension of crystallization in $\mathrm{Cu} / \mathrm{Pt}$ alloy nanoparticles (F. J. Yu et al. paper under preparation). It seems to be confirmed that the reversed crystal growth is a common phenomenon in the formation of various materials and more examples will be found in future research. 
Fig. 2 a TEM image of a zeolite A particle after crystal growth for $3 \mathrm{~h}$. b The same particle after annealing with the electron beam for a few minutes. Insets are the corresponding SAED patterns
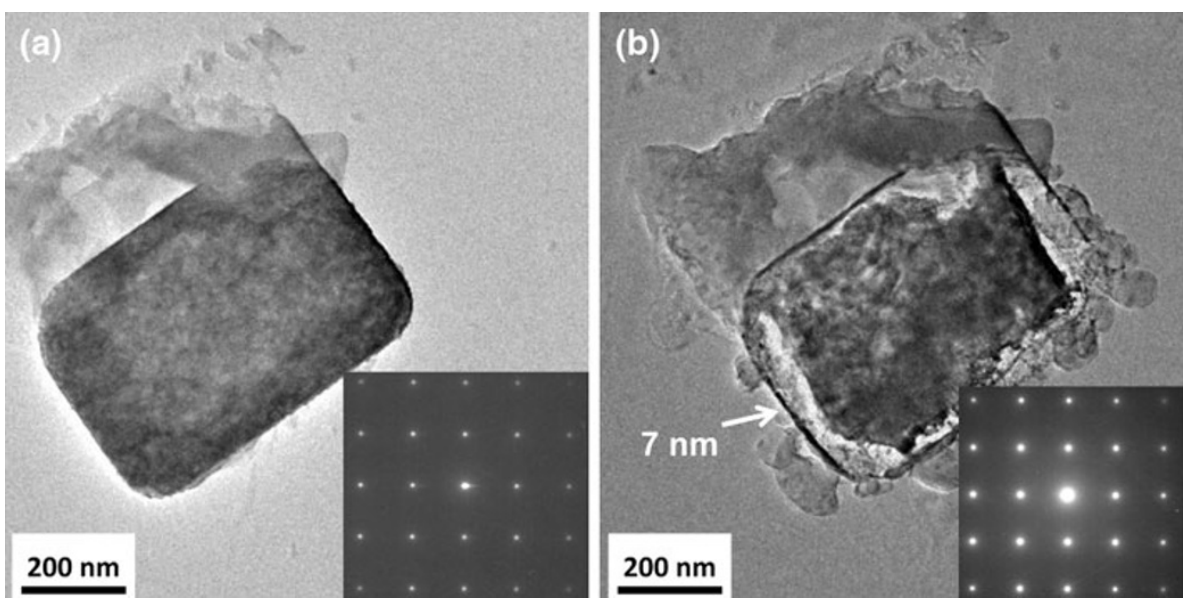

Fig. 3 TEM images of $\mathrm{CaTiO}_{3}$ particles with different crystalgrowth times: a 1, b 2, and c 5 h. d Low-magnification SEM image of the assynthesized $\mathrm{CaTiO}_{3}$ product prepared in the water-free poly(ethylene glycol) solution. The inset shows a corresponding cross-section TEM image of a particle showing a hollow structure. e SEM image of cubic $\mathrm{CaTiO}_{3}$ particles where the recrystallization and reversed growth was enhanced by adding 5 vol\% water. The inset is a higher magnification SEM image of a broken cube from the same specimen
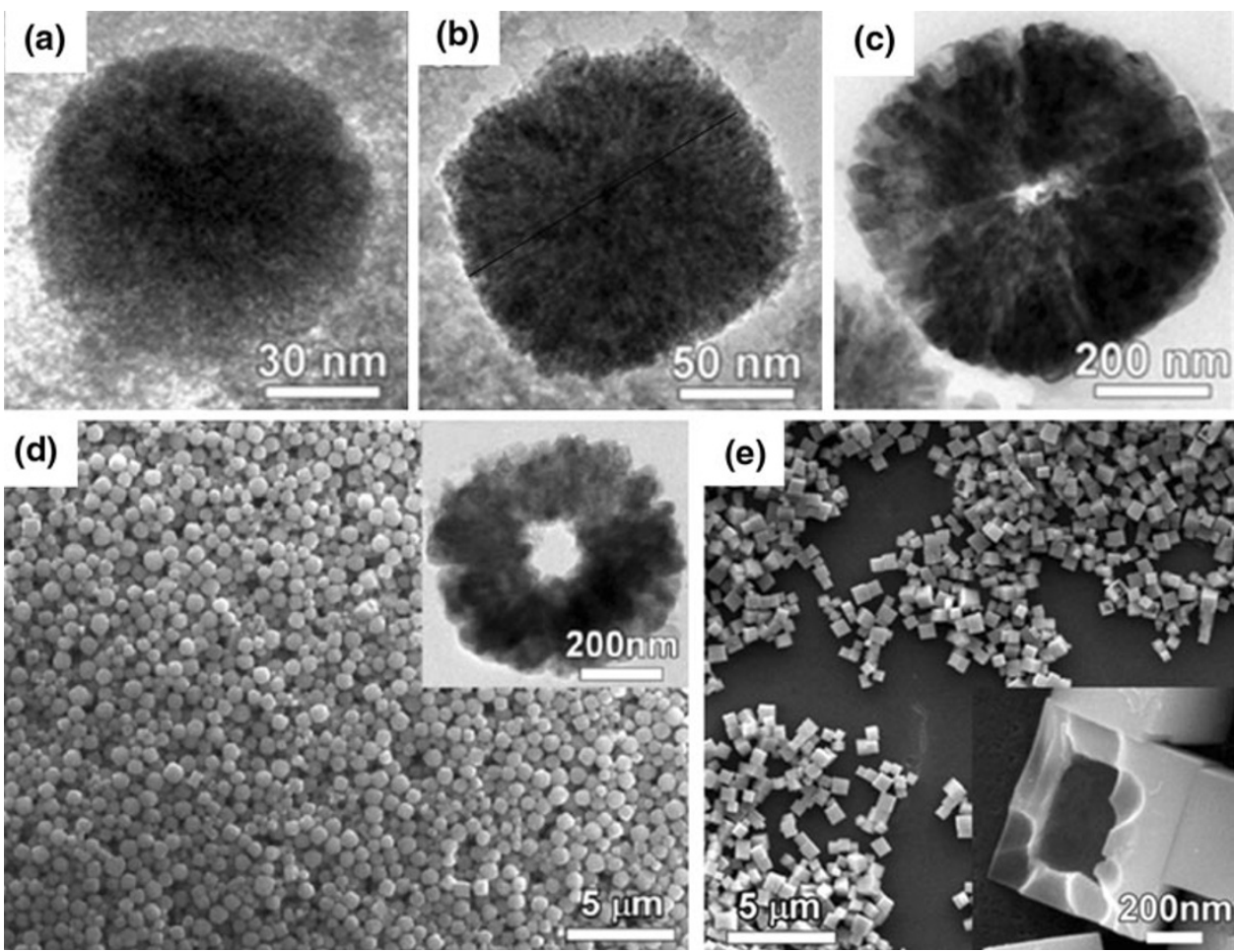

\section{Particles with novel hierarchical morphologies}

Electron microscopy has been used to search for some hidden particles in solids, which are key particles in the formation of novel hierarchical morphologies. Good examples are twin-crystals of $\mathrm{ZnO}$ and flower-like $\mathrm{BiOBr}$.

Wurtzite $\mathrm{ZnO}$ is an important semiconductor with a wide band gap of $3.37 \mathrm{eV}$ at room temperature and a large exciton binding energy of $60 \mathrm{meV}$. These properties make $\mathrm{ZnO}$ a good candidate to use in catalysis [12] and many other applications. Twin-crystals of $\mathrm{ZnO}$ was synthesized using $\mathrm{Zn}\left(\mathrm{NO}_{3}\right)_{2} \cdot 6 \mathrm{H}_{2} \mathrm{O}, \mathrm{C}_{6} \mathrm{H}_{12} \mathrm{~N}_{4}$, and gelatin (Fig. 4a) [13]. They formed by oriented stacking of $\mathrm{ZnO}$ nanoplates along the [001] zone axis. However, stacking of nanoplates normally leads to larger disk-like particles. An approximate mirror-symmetric manner of stacking implies a special microstructure in the centre of each particle. A similar growth manner was observed by Taubert et al. [14] in 2003. They used high-resolution transmission electron microscopy (HRTEM) to examine the central area of the particles and found a large number of defects in the central grain boundary. The formation mechanism or the origin of the central grain boundary was not revealed.

We then decided to investigate particles at early stages to try to reveal the microstructural evolution [15]. At beginning, the precursor molecules aggregated into some spherical amorphous particles (Fig. 4b). These particles crystallized into nanoplatelets of $\mathrm{Zn}_{5}\left(\mathrm{NO}_{3}\right)_{2}(\mathrm{OH})_{8} \cdot 2 \mathrm{H}_{2} \mathrm{O}$

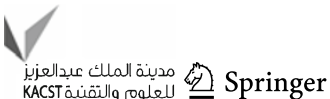


Fig. 4 a SEM image of the $\mathrm{ZnO}$ twin-crystals after growth for $21 \mathrm{~h}$. The inset is an enlarged SEM image with a profile view of a twin-crystal, showing nanoplates as building units. b A spherical particle at a very early stage with partial crystallization. c HRTEM image of a typical $\mathrm{Zn}_{5}\left(\mathrm{NO}_{3}\right)_{2}(\mathrm{OH})_{8} \cdot 2 \mathrm{H}_{2} \mathrm{O}$ nanoplatelet from the 10-min sample. The $d$-spacing of the fringes is about $0.321 \mathrm{~nm}$. d Enlarged TEM image of a single-layer nanoplate showing a porous nature. The inset is the corresponding SAED pattern indicating a highly ordered orientation of the nanoplatelets. e TEM image of single-

(bottom) and double- (top) layer nanoplates. f Schematic drawing showing a double-layer $\mathrm{ZnO}$ nanoplate attracting single-layer $\mathrm{ZnO}$ (yellow) or

$\mathrm{Zn}_{5}\left(\mathrm{NO}_{3}\right)_{2}(\mathrm{OH})_{8} \cdot 2 \mathrm{H}_{2} \mathrm{O}$ (blue) nanoplate
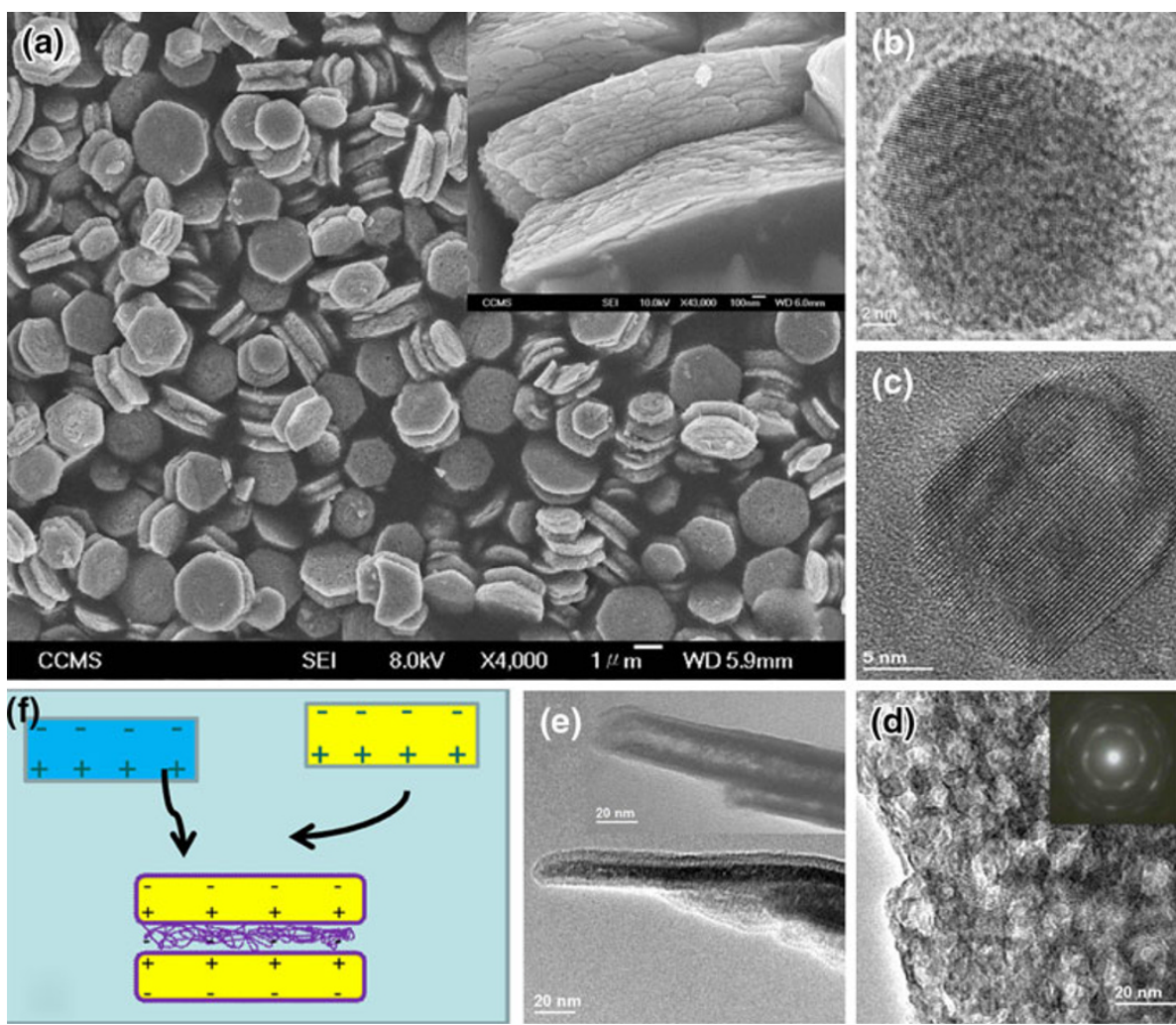

with a size about $15 \mathrm{~nm}$ (Fig. 4c), which then further aggregated into large nanoplates with a fairly good crystal orientation, although individual nanoplatelets inside the single-layer nanoplates are still distinguishable (Fig. 4d). The $d$-spacing of $0.321 \mathrm{~nm}$ observed in Fig. $4 \mathrm{c}$ can be indexed to the (020) planes of $\mathrm{Zn}_{5}\left(\mathrm{NO}_{3}\right)_{2}(\mathrm{OH})_{8} \cdot 2 \mathrm{H}_{2} \mathrm{O}$, but cannot be indexed to $\mathrm{ZnO}$. The most interesting structural evolution is that a phase transformation from $\mathrm{Zn}_{5}\left(\mathrm{NO}_{3}\right)_{2}(\mathrm{OH})_{8} \cdot 2 \mathrm{H}_{2} \mathrm{O}$ to $\mathrm{ZnO}$ took place on both surfaces of some single-layer nanoplates, leading to double-layer nanoplates separated by a layer of gelatin molecules (Fig. 4e). This is the first example of the reversed crystalgrowth route in nanoplates. Because the gelatin molecules were negatively charged in the synthetic solution with a $\mathrm{pH}$ value in a range of $6.2-8$, the inner surfaces of the two $\mathrm{ZnO}$ layers in the double-layer nanoplates were positively charged and both the outer surfaces were negatively charged. Consequently, this structure of dipolar $\mathrm{ZnO}$ made stacking of these double-layer nanoplates very difficult. On the other hand, single-layer nanoplates of $\mathrm{Zn}_{5}\left(\mathrm{NO}_{3}\right)_{2}(\mathrm{OH})_{8} \cdot 2 \mathrm{H}_{2} \mathrm{O}$ can stack on the surface of the double-layer nanoplates much more easily (Fig. 4f). Such self-assembly on both surface of double-layer nanoplates followed by a complete phase transformation resulted in the so-called twin-crystals of $\mathrm{ZnO}$. In the final products, the original double-layer core particles cannot be distinguished from other $\mathrm{ZnO}$ nanoplates.
We learnt from this work that to form twin-crystals, two different particles must form independently in the synthetic system, i.e. single-layer and double-layer nanoplates. The former is the building unit and the latter is the core. They can have the same crystal phase, but different microstructures or superstructures with different electrochemical properties. The ratio of the building units and the core particles must be large so that each twin-crystal can form by the stacking of hundreds of building units (single-layer nanoplates) on only one core particle (double-layer nanoplate). Finally, the double-layer core is the key particle for this hierarchical morphology. However, in the final twincrystals, it grows with other single-layer nanoplates and becomes indistinguishable.

Flower-like $\mathrm{BiOBr}$ crystals synthesized by $\mathrm{Z}$. Jiang et al. (paper under preparation) in Oxford shows another novel hierarchical morphology (Fig. 5a), which drew our attention recently. The specimens were prepared via a mixture of $\mathrm{KBr}$ and $\mathrm{Bi}\left(\mathrm{NO}_{3}\right)_{3} \cdot 5 \mathrm{H}_{2} \mathrm{O}$ aqueous solutions followed by ultrasonic treatment. Each particle consists of many small nanoplates, stacking in a non-parallel way, ensuring a large exposed surface, which is beneficial in photocatalysis. To understand its formation mechanism, we also examined microstructures of specimens at different growth stages. We found it is essential to have two types of $\mathrm{BiOBr}$ particles with different morphologies so that a flower-like particle can form. One is a large hollow nanoplate 
Fig. 5 a SEM image of a flower-like $\mathrm{BiOBr}$ particle. b TEM image of a typical large hollow plate, which acts as a base for a flower-like particle. c SEM image of broccoli-like $\mathrm{CaCO}_{3}$ particle. d SEM image of a half broccoli-like particle, showing the central nanoplate
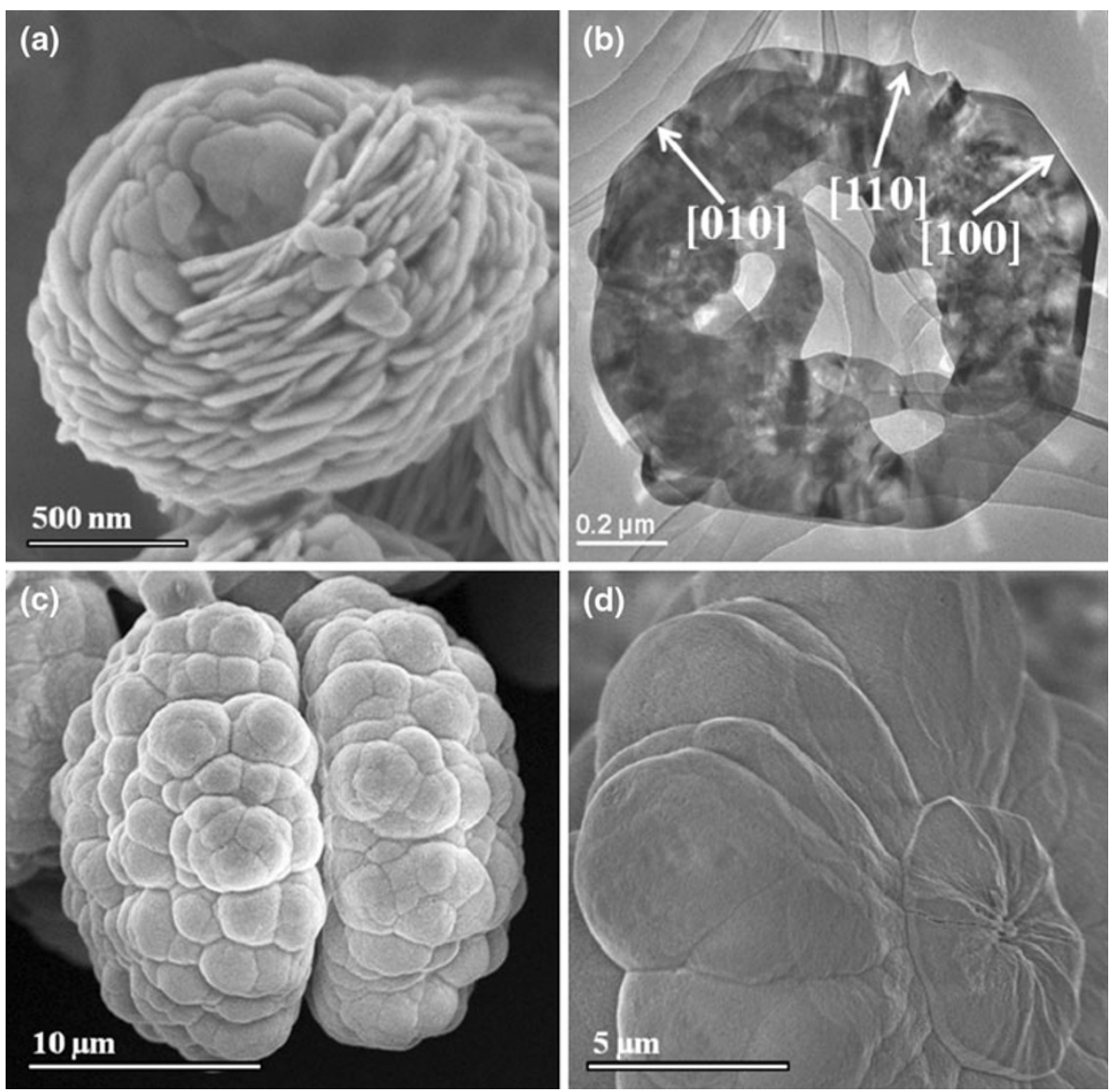

servicing as the flower base (Fig. 5b). The other is small solid nanoplate acting as the flower petal. Post-reaction aging and sonochemical treatment were crucial in the formation of large hollow plates.

Figure 5c shows a broccoli-like $\mathrm{CaCO}_{3}$ particle developed from a spherical particle. This morphology change, similar to a cell-division process, is the most important step in a continuous morphology evolution from spherical to a hexagonal prism. The driving force of this change has been found from a central microdisk as shown in Fig. 5d (H. F. Greer, et al. paper in preparation).

As we see from the above examples, formation of some complex hierarchical microstructures requires two types of pre-formed building units. The central hidden particles are crucial, but are often ignored by people. One of the difficulties is that these particles have the same crystal phases as the main building units. It is even more difficult to detect them when they become indistinguishable during the crystal growth (see the case of $\mathrm{ZnO}$ ). We found HRTEM investigations of the early-stage crystal growth is a very powerful method to discover these hidden particles and to understand the detailed formation mechanisms of some solid materials with novel morphologies.

\section{Soot particles in a candle flame}

High-resolution transmission electron microscopy technique has also been used to detect some 'hidden' particles in a candle flame. Candles have a history of over 2,000 years. Candle flame as a research subject has also a long history of several hundred years. However, the soot particles inside a candle flame are not well known. The main problem is that we do not have a good sampling method. If we can collect the soot particles from a candle flame with their original states intact, we may investigate their structures using HRTEM.

When we inserted a thin film of porous anodic aluminium oxide (AAO) with both ends of the pores open into a candle flame for $1 \mathrm{~s}$ and removed it quickly, some soot particles smaller than the pore size would enter the pores and further reaction of these particles would be stopped. The particles were then transferred by an ultrasonic treatment into a solution and further transferred to a microscopic specimen grid. We found the structures of the soot particles collected from different positions of a candle flame were different. In particular, all four well-known carbon structural types were observed from the middle position of the candle flame as shown in Fig. 6, i.e.

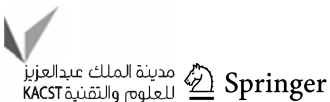


Fig. 6 HRTEM images of some nanoparticles collected from a central position of a candle flame, a graphitic spheres, b graphitic spheres with nanodiamond particles, $\mathbf{c}$ a nanodiamond particle surrounded by amorphous carbon compounds, and d fullerene particles on the graphitic surface indicated by the arrows
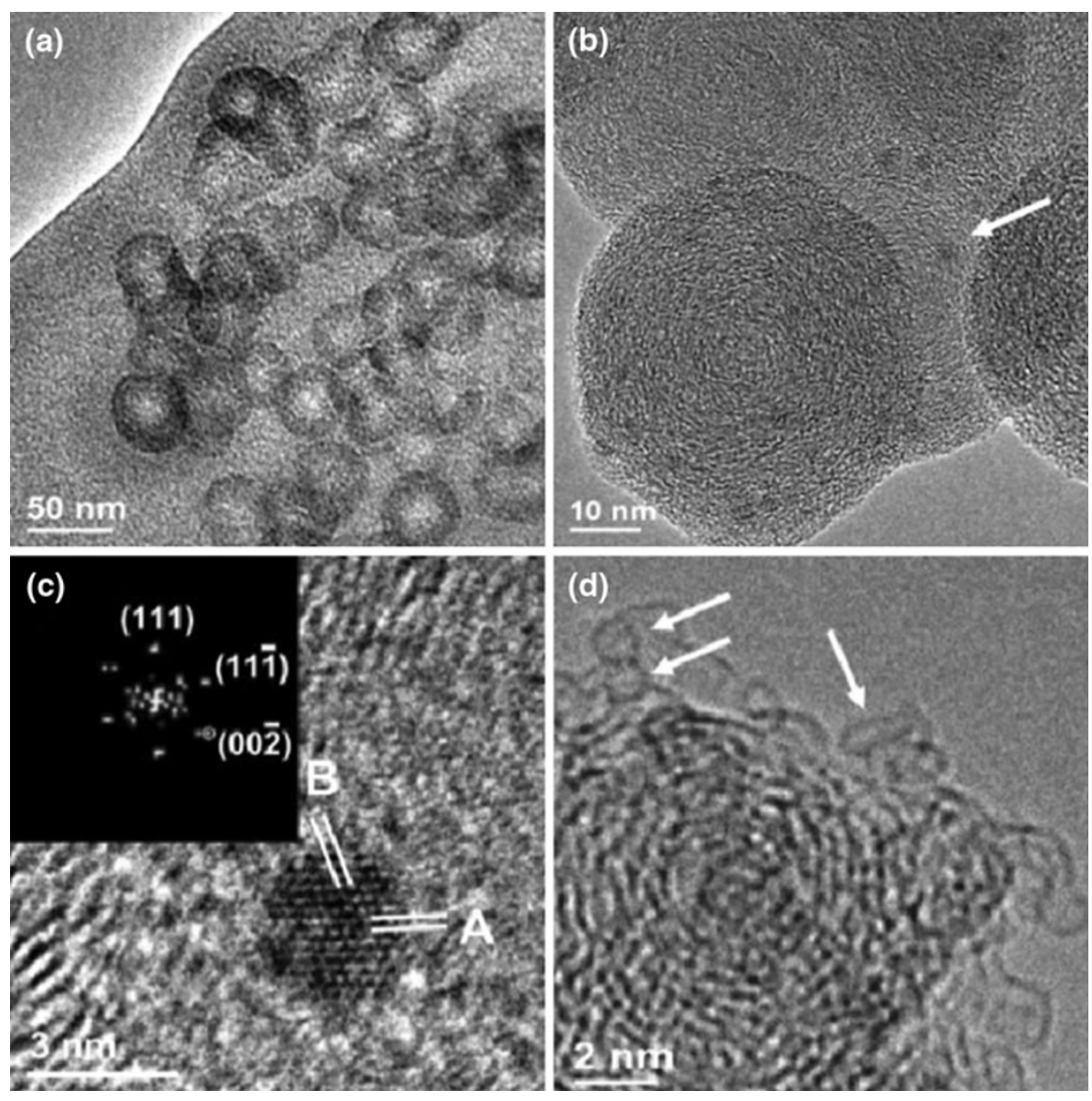

amorphous, graphitic, fullerenic and nanodiamond particles [16]. This work may indicate a new formation mechanism of diamond. More importantly, improved knowledge of the soot particles in combustion may help us to better understand the chemical reactions in combustion, including the formation of $\mathrm{NO}_{x}$ particles.

In summary, electron microscopic studies can reveal more details of crystal growth. The discoveries of reversed crystal-growth route and some hidden particles give us more freedom to control the morphologies of catalytic materials. It can be expected the research in this field will be continuously active in the future.

Open Access This article is distributed under the terms of the Creative Commons Attribution License which permits any use, distribution, and reproduction in any medium, provided the original author(s) and the source are credited.

\section{References}

1. Bravais A (1866) Études Crystallographic. Gauthier-Villars, Paris

2. Friedel MG (1907) Études sur la loi de Bravais. Bull Soc Fr Mineral Cristallogr 30:326

3. Donnay JDH, Harker D (1937) A new law of crystal morphology extending the law of Bravais. Am Mineral 22:446
4. Chen XY, Qiao MH, Xie SH, Fan KN, Zhou WZ, He HY (2007) Self-construction of core-shell and hollow zeolite analcime icositetrahedra: a reversed crystal growth process via oriented aggregation of nanocrystallites and recrystallization from surface to core. J Am Chem Soc 129:13305

5. Greer H, Wheatley PS, Ashbrook SE, Morris RE, Zhou WZ (2009) Early stage reversed crystal growth of zeolite A and its phase transformation to sodalite. J Am Chem Soc 131:17986

6. Yao JF, Li D, Zhang XY, Kong CH, Yue WB, Zhou WZ, Wang HT (2008) Cubes of zeolite A with an amorphous core. Angew Chem Int Ed 47:8397

7. Yang XF, Fu JX, Jin CJ, Liang CL, Wu MM, Zhou WZ (2010) Formation mechanism of $\mathrm{CaTiO}_{3}$ hollow crystals with different microstructures. J Am Chem Soc 132:14279

8. Zhan HQ, Yang XF, Wang CM, Chen J, Wen YP, Liang CL, Greer HF, Wu MM, Zhou WZ (2012) Multiple nucleation and crystal growth of barium titanate. Cryst Growth Des 12:1247

9. Xie SH, Zhou WZ, Zhu YQ (2004) Formation mechanism of $\mathrm{Mg}_{2} \mathrm{SiO}_{4}$ fishbone-like fractal nanostructures. J Phys Chem B 108:11561

10. Sander JRG, Bučar D-K, Baltrusaitis J, MacGillivray LR (2012) Organic nanocrystals of the resorcinarene hexamer via sonochemistry: evidence of reversed crystal growth involving hollow morphologies. J Am Chem Soc 134:6900

11. Zhou WZ (2010) Reversed crystal growth: implications for crystal engineering. Adv Mater 22:3086

12. Zhou H, Fan T, Li X, Zhang D, Guo Q, Ogawa H (2009) Biomimetic photocatalyst system derived from the natural prototype in leaves for efficient visible-light-driven catalysis. J Mater Chem 19:2695 
13. Tseng Y-H, Lin H-Y, Liu M-H, Chen Y-F, Mou C-Y (2009) Biomimetic synthesis of nacrelike faceted mesocrystals of $\mathrm{ZnO}-$ gelatin composite. J Phys Chem C 113:18053

14. Taubert A, Kubel C, Martin DC (2003) Polymer-induced microstructure variation in zinc oxide crystals precipitated from aqueous solution. J. Phys. Chem. B. 107:2660
15. Greer HF, Zhou WZ, Liu MH, Tseng YH, Mou CY (2012) The origin of $\mathrm{ZnO}$ twin crystals in bio-inspired synthesis. CrystEngComm 14:1247

16. Su ZX, Zhou WZ, Zhang Y (2011) New insight into the soot nanoparticles in a candle flame. Chem Commun 47:4700 